\title{
TEORIA DAS JANELAS QUEBRADAS E SUA APLICAÇÃO NO CAMPO PRÁTICO POR MEIO DA POLÍTICA DE TOLERÂNCIA ZERO
}

\author{
Rômulo Henrique Godoi Sendrete ${ }^{1}$ \\ Paulo Celso Ayrosa Monteiro de Andrade ${ }^{2}$
}

Resumo: Com o frequente aumento da criminalidade no Brasil e com a falta de soluções e programas capazes de contê-la, o presente artigo procura realizar um estudo sobre a Teoria das Janelas Quebradas, que aponta a desordem como um dos principais fatores para a prática de crimes, e a sua aplicação no campo prático por meio da política de Tolerância Zero, consistente na repressão total de todo e qualquer delito, ambas de origem norte-americana, aplicadas em alguns lugares do mundo para conter a criminalidade. Objetiva-se, ainda, analisar brevemente a situação brasileira no combate à criminalidade, especialmente no tocante a aplicação dos princípios da intervenção mínima e da insignificância, que excluem da incidência do Direito Penal os pequenos delitos. Por fim, estudar a possibilidade e a eficácia da aplicação da Teoria e Política no Brasil.

Palavras-chave: Criminalidade; Desordem; Janelas quebradas; Penal. 